\title{
Effects of lithium chloride on rabbit blastocyst expansion, and accumulation of phosphoinositides and inositol phosphates
}

\author{
M. M. Fahy* and M. T. Kane ${ }^{\dagger}$ \\ Department of Physiology, University College, Galway, Ireland
}

\begin{abstract}
The effects of lithium, an inhibitor of the recycling of inositol in the phosphatidylinositol cycle, on rabbit blastocyst growth and metabolism of phosphoinositides were investigated. Day 2 rabbit morulae were first cultured for 2 days in basic culture medium and then transferred to medium containing myo-[2- $\left.{ }^{3} \mathrm{H}\right]$ inositol for culture for a further 3 days. At the end of culture, the resulting blastocysts were incubated with $\mathrm{LiCl}\left(0,1,5,10,20 \mathrm{mmol}^{-1}\right)$ for $1 \mathrm{~h}$. The blastocysts were then lysed and both the aqueous and lipid portions were analysed for incorporated radioactivity. Thin layer chromatographic separation of the lipid portion indicated that lithium had no significant effect on formation of radiolabelled phosphoinositides. However, high performance anion exchange chromatography indicated that lithium significantly stimulated accumulation of radiolabelled inositol monophosphate and inositol 1,4,5-trisphosphate. This result indicates that the phosphatidylinositol cycle is turning over in rabbit blastocysts. Continuous culture of rabbit embryos for 5 days in media containing $\mathrm{LiCl}\left(5,10,15\right.$ and $\left.20 \mathrm{mmol} \mathrm{l}^{-1}\right)$ significantly decreased blastocyst growth as measured by blastocyst expansion and incorporation of $\left[{ }^{3} \mathrm{H}\right]$ thymidine. However, supplementing the medium with excess inositol (up to $9375 \mu \mathrm{mol} \mathrm{I}^{-1}$ ), in an attempt to increase the intracellular uptake of inositol and thus compensate for the inhibitory effect of lithium on inositol recycling, did not reverse the inhibitory effect of lithium on blastocyst growth.
\end{abstract}

\section{Introduction}

There is great interest in the role of the phosphatidylinositol (PtdIns) cycle as a controlling system for cell proliferation in a wide range of both normal and cancer cells (reviewed by Berridge, 1987, and Tilly and Moolenaar, 1989). In the PtdIns cycle inositol is incorporated into PtdIns, which is converted to the polyphosphoinositides, PtdIns $4 \mathrm{P}$ and $\operatorname{PtdIns}(4,5) \mathrm{P}_{2}$. Stimulation of cells by certain growth factors results in production of two second messengers, diacylglycerol and inositol 1,4,5trisphosphate $\left(\operatorname{Ins}(1,4,5) \mathrm{P}_{3}\right)$ from $\mathrm{PtdIns} \mathrm{P}_{2}$. The $\operatorname{Ins}(1,4,5) \mathrm{P}_{3}$ is metabolized to inositol monophosphate (InsP) and the cycle is completed by the breakdown of this to free inositol which may then be recycled. Lithium is known to disrupt the cycle by inhibiting the enzyme that breaks down inositol monophosphate (Hallcher and Sherman, 1980) and thus deprives the cell of inositol for phosphoinositide synthesis by preventing normal intracellular recycling of inositol.

There is some evidence that the PtdIns cycle plays a role in oocyte activation (reviewed by Whitaker, 1989) and in control of development in the early embryo (reviewed by Busa, 1988). Injection of lithium ions into blastomeres of the 32-cell Xenopus embryo disrupts normal development and this effect is prevented by coinjection of myo-inositol. Treatment of cultured mouse embryos with lithium inhibits formation of the inner cell

\footnotetext{
*Present address: Division of Neuroscience, Oregon Regional Primate Center, Beaverton, OR 97006, USA.

${ }^{+}$Correspondence and reprint requests.

Received 18 January 1993.
}

mass but not of the trophectoderm (Izquierdo and Becker, 1982). We showed that inositol is essential for growth and expansion of rabbit blastocysts (Kane, 1989; Fahy and Kane, 1992) and hatching of hamster blastocysts (Kane and Bavister, 1988) and also found evidence for the incorporation of $\left[{ }^{3} \mathrm{H}\right]$ inositol into phosphoinositides by mouse and rabbit blastocysts, and into inositol phosphates (including $\left.\operatorname{Ins}(1,4,5) \mathrm{P}_{3}\right)$ by rabbit blastocysts (Kane et al., 1992; Fahy and Kane, 1993).

In the present experiments, the in vitro effects of lithium chloride on rabbit blastocyst expansion and accumulation of inositol phosphates and phosphoinositides were investigated. We also examined whether the effects of lithium on blastocyst growth could be reversed by addition of high concentrations of inositol to the culture medium.

\section{Materials and Methods}

\section{Embryo culture and radiolabelling with $\left.{ }^{3} \mathrm{H}\right]$ inositol and [3]H]thymidine}

Early morulae were collected from the oviducts of superovulated New Zealand White does $44-48 \mathrm{~h}$ after hCG injection and insemination (Kane, 1987) and cultured in $1 \mathrm{ml}$ culture medium under paraffin liquid (Merck, Darmstadt) in the wells of 24-well tissue culture plates (Costar, Badhoevedorp). Basic medium composition was $0.5 \%$ BSA (w/v), $108 \mathrm{mmol}$ $\mathrm{NaCl} \mathrm{l}^{-1}, 4.78 \mathrm{mmol} \mathrm{KCl} \mathrm{l}{ }^{-1}, 1.71 \mathrm{mmol} \mathrm{CaCl} \cdot 2 \mathrm{H}_{2} \mathrm{O} \mathrm{l}^{-1}$, 
$1.19 \mathrm{mmol} \mathrm{KH}_{2} \mathrm{PO}_{4} 1^{-1}, 1.19 \mathrm{mmol} \mathrm{MgSO}_{4} \cdot 7 \mathrm{H}_{2} \mathrm{O} \mathrm{l}^{-1}$ $25 \mathrm{mmol} \mathrm{NaHCO}{ }_{3} 1^{-1}, 0.5 \mathrm{mmol}$ sodium pyruvate $\mathrm{I}^{-1}$ and $1 \mathrm{mmol}$ glucose $\mathrm{1}^{-1}$. The concentrations of amino acids, vitamins and trace elements were as in Ham's F10 medium (Ham, 1963) with minor modifications (Fahy and Kane, 1992). Where additions (inositol or $\mathrm{LiCl}$ ) were made to the medium, osmolarity was maintained by adjustment of the $\mathrm{NaCl}$ concentration.

In some experiments, embryos were cultured with $\left[6-{ }^{3} \mathrm{H}\right]$ thymidine as an index of DNA synthesis and cell proliferation and with myo-[2- $\left.{ }^{3} \mathrm{H}\right]$ inositol (both from NEN, Dupont, $20 \mathrm{Ci} \mathrm{mmol}^{-1}$ ) to label phosphoinositides and inositol phosphates. Embryos cultured to the blastocyst stage in radiolabel were washed free of excess radioactivity at the end of culture by three transfers to medium without radioactive compounds. Blastocysts labelled with $\left[{ }^{3} \mathrm{H}\right]$ thymidine were processed as described by Fahy and Kane (1992) and radioactivity was measured in a scintillation counter. The results are quoted as the c.p.m. values because of the difficulty of converting c.p.m. to d.p.m. owing to self absorption by filters (Simonnet, 1990).

Blastocysts labelled with $\left[{ }^{3} \mathrm{H}\right]$ inositol were precipitated and separated into an aqueous inositol phosphate-containing supernatant phase and a membranous phospholipid-containing pellet as described by Fahy and Kane (1993). The pellet and supernatant were then treated separately for analysis of phosphoinositides and inositol phosphates, respectively.

\section{Analysis of phosphoinositides}

The phospholipids were extracted from the membrane pellet essentially as described by Roldan and Harrison (1989), except that perchloric acid was substituted for trichloroacetic acid throughout. The phospholipids were then separated by thin layer chromatography (TLC); the various radiolabelled phosphoinositides were identified on the basis of co-migration with known unlabelled standards; and the spots were scraped and radioactivity measured in a scintillation counter (Fahy and Kane, 1993).

\section{Analysis of inositol phosphates}

The supernatant from perchloric acid-extracted rabbit blastocysts was treated with a 1:1 mixture of freon:tri- $n$ octylamine (v:v) (Harrison et al., 1990) to remove perchloric acid. The inositol phosphates were then separated on a Pharmacia HPLC Mono Q HR5/5 anion exchange column (Milton Keynes) using a gradient elution system (Meek and Nicoletti, 1986; Fahy and Kane, 1993). Both eluant A and B contained $0.1 \mathrm{mmol} \mathrm{ZnSO}_{4} 1^{-1}, 0.1 \mathrm{mmol}$ EDTA $\mathrm{l}^{-1}$ and $10 \mathrm{mmol}$ Hepes $1^{-1}$; eluant $B$ also contained $500 \mathrm{mmol}$ $\mathrm{Na}_{2} \mathrm{SO}_{4} \mathrm{I}^{-1}$. Before analysis of blastocyst extracts, the column and elution system were standardized using nucleotides (AMP, ADP, ATP, adenosine tetra-phosphate, GMP, GDP, GTP and guanosine tetraphosphate) and HPLC-pure $\left[{ }^{3} \mathrm{H}\right]$ inositol phosphates $\left(\operatorname{Ins}(4) \mathrm{P}, \operatorname{Ins}(1,4) \mathrm{P}_{2}, \operatorname{Ins}(1,4,5) \mathrm{P}_{3}\right.$ and $\operatorname{Ins}(1,3,4,5) \mathrm{P}_{4} ; \mathrm{NEN}$, Dupont) as markers. These nucleotide markers were also used to spike all samples from blastocyst extracts as a check on the repeatability of standardization and sample chromatographic runs. All runs were monitored at $254 \mathrm{~nm}$ to detect the nucleotides. Column eluate from both standardization and sample runs was collected in $1 \mathrm{ml}$ fractions, and radioactivity of these samples was measured in a scintillation counter.

\section{Statistical analysis}

The results of experiments were analysed by analysis of variance (Steel and Torrie, 1960). Data were further analysed by orthogonal comparisons (Expts 1 and 2) to test for linear and quadratic regression effects (Steel and Torrie, 1960).

\section{Experiments and Results}

\section{Experiment 1: effects of lithium chloride on the accumulation of phosphoinositides and inositol phosphates in rabbit blastocysts}

Morulae were cultured for 2 days in basic culture medium followed by 3 days in medium containing $5 \mu \mathrm{Ci}$ $\left[{ }^{3} \mathrm{H}\right]$ inositol $\mathrm{ml}^{-1}$. After the 3 day labelling period, the blastocysts were washed three times in non-radioactive Hepesbuffered flushing medium and transferred to culture medium containing various concentrations of $\mathrm{LiCl}\langle 0,1,5,10$, $20 \mathrm{mmol}^{-1}$ ) for $1 \mathrm{~h}$. At the end of the incubation, the blastocysts were washed free of labelled medium, the phosphoinositides and inositol phosphates extracted and fractioned, and the accumulation of $\left[{ }^{3} \mathrm{H}\right]$ inositol in the various fractions measured. After separation by TLC of the lipid extracts of rabbit blastocysts cultured for 3 days in $\left[{ }^{3} \mathrm{H}\right]$ inositol, most radioactivity co-migrated with PtdIns and small amounts comigrated with the $\operatorname{PtdIns}(4) \mathrm{P}$ and $\operatorname{PtdIns}(4,5) \mathrm{P}_{2}$ standards. There was no effect of $\mathrm{LiCl}$ on accumulation of radioactivity in any of the phosphoinositides (Table 1).

After separation of the perchloric acid extracts of blastocysts on a Pharmacia HPLC Mono $Q$ anion exchange column, peaks of radioactivity were found in fractions eluting at the same positions as $\operatorname{Ins} P, \operatorname{Ins}(1,4) \mathrm{P}_{2}, \operatorname{Ins}(1,4,5) \mathrm{P}_{3}$, and $\operatorname{Ins}(1,3,4,5) \mathrm{P}_{4}$ tritium-labelled standards (Fig. 1; Table 2). There were also peaks of radioactivity that had the same elution position relative to both inositol phosphate and nucleotide standards as was found for $\operatorname{Ins}(1,3) \mathrm{P}_{2}$, glycero-3-phospho-1-inositol bisphosphate and $\operatorname{Ins}(1,3,4) \mathrm{P}_{3}$ by Meek (1986) and Batty et al. (1989). Treatment of blastocysts with $\mathrm{LiCl}$ for $1 \mathrm{~h}$ at the end of culture had a marked effect on the uptake of radioactivity into a number of inositol phosphate fractions. Treatment with $20 \mathrm{mmol} \mathrm{LiCl} \mathrm{l}^{-1}$ resulted in a threefold increase in accumulated InsP compared with the control treatment without $\mathrm{LiCl}$ (Fig. 1; Table 2) and concentrations of $\mathrm{LiCl}$ from $1-20 \mathrm{mmol} 1^{-1}$ significantly $(P<0.05)$ increased InsP in a linear manner (Table 2; Fig. 2). $\mathrm{LiCl}$ also caused a much less marked (Table 2) but nevertheless significant linear increase $(P<0.05)$ in the second messenger $\operatorname{Ins}(1,4,5) \mathrm{P}_{3}$. There was no significant effect on the concentration of the other putative second messenger, $\operatorname{Ins}(1,3,4,5) \mathrm{P}_{4}$. In this case the high concentration in the control treatment without $\mathrm{LiCl}$ compared with the $\mathrm{LiCl}$ treatments is due to a single high value in one replicate of the control lithium-free treatment.

\section{Experiment 2: effect of prolonged culture in lithium chloride on rabbit blastocyst expansion and DNA synthesis}

Morulae were cultured for 5 days in medium containing various concentrations of lithium chloride $(0,5,10$ and 
Table 1. Effect of treatment with lithium chloride on incorporation of $\left[{ }^{3} \mathrm{H}\right]$ inositol into phosphoinositides by rabbit blastocysts

\begin{tabular}{lrrrrr}
\hline & \multicolumn{5}{c}{$\mathrm{LiCl}\left(\mathrm{mmol} \mathrm{I}^{-1}\right)$} \\
\cline { 2 - 6 } Phosphoinositides & \multicolumn{1}{c}{0} & \multicolumn{1}{c}{$\mathrm{I}$} & \multicolumn{1}{c}{10} & 20 \\
\hline PtdIns & & & & & \\
PtdIns(4)P & $4767 \pm 45$ & $4539 \pm 56$ & $4513 \pm 62$ & $5182 \pm 78$ & $4989 \pm 58$ \\
PtdIns(4,5)P & $153 \pm 21$ & $196 \pm 36$ & $166 \pm 22$ & $225 \pm 52$ & $169 \pm 26$ \\
& $125 \pm 14$ & $157 \pm 29$ & $147 \pm 21$ & $173 \pm 34$ & $149 \pm 20$ \\
\hline
\end{tabular}

Values are means (d.p.m. per blastocyst) \pm SEM for four replicates of 21-25 blastocysts per replicate (a total of $90-92$ blastocysts for each treatment). The identification of phosphoinositides (PtdIns) is based on incorporation of radioactivity into spots which co-migrated with phosphoinositide standards on TLC There was no significant effect of $\mathrm{LiCl}$ on incorporation into the phosphoinositides $(P>0.05)$.

$\left.20 \mathrm{mmol}^{-1}\right)$. All treatments contained $15 \mu \mathrm{mol}$ inositol $1^{-1}$. After culture for 5 days, blastocyst diameters were measured with an eye-piece micrometer and the blastocysts were incubated with $\left[{ }^{3} \mathrm{H}\right]$ thymidine for $5 \mathrm{~h}$ to determine DNA synthesis as an index of cell proliferation. Prolonged culture of embryos in $\mathrm{LiCl}$ drastically inhibited blastocyst expansion and cell proliferation; blastocyst diameter and $\left[{ }^{3} \mathrm{H}\right]$ thymidine uptake decreased linearly from 0 to $20 \mathrm{mmol} \mathrm{LiCl} \mathrm{I}^{-1}$ (Fig. 3, $P<0.01$ ). Treatment with $20 \mathrm{mmol} \mathrm{LiCl} \mathrm{l}^{-1}$ for 5 days decreased mean blastocyst diameter to $143 \mu \mathrm{m}$ from $535 \mu \mathrm{m}$ in the control lithium-free medium and decreased uptake of $\left[{ }^{3} \mathrm{H}\right]$ thymidine to 21 c.p.m. from 807 c.p.m. per blastocyst in the control medium.

\section{Experiment 3: effects of prolonged culture in lithium chloride and} high concentrations of inositol on blastocyst expansion

Morulae were cultured for 5 days in media containing 10 or $20 \mathrm{mmol} \mathrm{LiCl} 1^{-1}$ plus various concentrations of inositol in an attempt to reverse the inhibitory effects of lithium. The effects of $10 \mathrm{mmol} \mathrm{LiCl} 1^{-1}$ in the presence of $15,75,375,1875$ and $9375 \mu \mathrm{mol}$ inositol $1^{-1}$ were compared with a control lithiumfree medium with $15 \mu \mathrm{mol}$ inositol $\mathrm{l}^{-1}$ (Fig. 4a), and the effects of $20 \mathrm{mmol} \mathrm{LiCl}^{-1}$ in the presence of 75,375 , and $1875 \mu \mathrm{mol}$ inositol $1^{-1}$ were compared with a control lithium-free medium with $75 \mu \mathrm{mol}$ inositol $1^{-1}$ (Fig. 4b) and the effects of $20 \mathrm{mmol}$ $\mathrm{LiCl} \mathrm{l}^{-1}$ in the presence of $15,75,375,1875$ and $9375 \mu \mathrm{mol}$ inositol $l^{-1}$ were compared with a control lithium-free medium with $75 \mu \mathrm{mol}$ inositol $\mathrm{l}^{-1}$ (Fig. 4c). Blastocyst diameters were measured at the end of the 5 day culture.

Blastocyst growth as measured by blastocyst expansion was drastically inhibited by lithium in all three experiments (Fig. 4). However, in all experiments high concentrations of inositol in the medium failed to reverse the inhibition of blastocyst growth caused by lithium. Thus the experiments failed to show that the lithium-induced growth inhibition was necessarily related to lithium effects on recycling of inositol.

\section{Discussion}

The data reported here show that short-term treatment with lithium, which inhibits inositol recycling within cells by block-
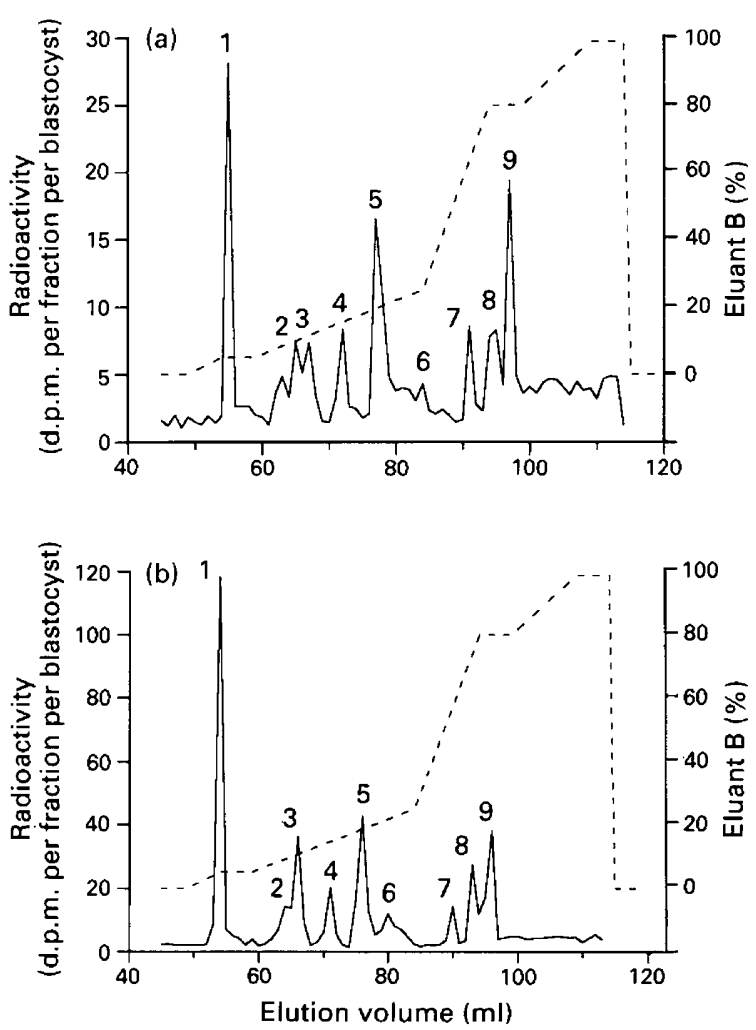

Fig. 1. Elution profiles of radiolabelled inositol phosphates extracted from rabbit blastocysts incubated in (a) the absence and (b) the presence of lithium chloride $\left(20 \mathrm{mmol} \mathrm{l}^{-1}\right)$ for $1 \mathrm{~h}$, and separated on an HPLC anion exchange column. The sample applied to the column for each profile was extracted from 21 blastocysts. On the basis of their elution at the positions of HPLC-pure $\left[{ }^{3} \mathrm{H}\right]$ inositol phosphate standards, the following peaks were identified:- peak 1 : Ins(4)P; peak 3: $\operatorname{Ins}(1,4) \mathrm{P}_{2} ;$ peak 6 : $\operatorname{Ins}(1,4,5) \mathrm{P}_{3}$ and peak $7: \operatorname{Ins}(1,3,4,5) \mathrm{P}_{4}$. On the basis of their positions relative to inositol phosphate and nucleotide standards, the following peaks were also tentatively identified - peak 2: $\operatorname{Ins}(1,3) \mathrm{P}_{2}$; peak 4: glycero-3-phospho-1-inositol bisphosphate and peak 5: Ins $(1,3,4) \mathrm{P}_{3}$. Peaks 8 and 9 are unknown compounds. Note the difference in scales for the two profiles. Both profiles are from the same replicate.

ing inositol monophosphatase (Sherman, 1989), caused an increased accumulation of InsP in rabbit blastocysts. The fact 
Table 2. Effect of treatment with lithium chloride on incorporation of $\left[{ }^{3} \mathrm{H}\right]$ inositol into inositol phosphates by rabbit blastocysts

\begin{tabular}{|c|c|c|c|c|c|}
\hline \multirow[b]{2}{*}{ Peak } & \multicolumn{5}{|c|}{$\mathrm{LiCl}$ concentration $\left(\mathrm{mmol} \mathrm{l}{ }^{-1}\right)$} \\
\hline & 0 & 1 & 5 & 10 & 20 \\
\hline 1. InsP & $98 \pm 23$ & $149 \pm 12$ & $219 \pm 9$ & $219 \pm 28$ & $292 \pm 33$ \\
\hline 2. & $48 \pm 9$ & $54 \pm 16$ & $43 \pm 6$ & $51 \pm 19$ & $71 \pm 24$ \\
\hline 3. $\operatorname{Ins}(1,4) \mathrm{P}_{2}$ & $60 \pm 9$ & $63 \pm 12$ & $67 \pm 13$ & $69 \pm 19$ & $89 \pm 10$ \\
\hline 4. & $63 \pm 13$ & $62 \pm 10$ & $71 \pm 12$ & $52 \pm 12$ & $74 \pm 6$ \\
\hline 5. & $148 \pm 30$ & $147 \pm 23$ & $154 \pm 20$ & $144 \pm 34$ & $160 \pm 16$ \\
\hline 6. $\operatorname{Ins}(1,4,5) \mathrm{P}_{3}$ & $47 \pm 13$ & $52 \pm 7$ & $68 \pm 3$ & $66 \pm 7$ & $74 \pm 6$ \\
\hline 7. $\operatorname{Ins}(1,3,4,5) \mathrm{P}_{4}$ & $117 \pm 94$ & $44 \pm 20$ & $30 \pm 7$ & $24 \pm 2$ & $44 \pm 5$ \\
\hline 8. & $38 \pm 6$ & $47 \pm 5$ & $39 \pm 6$ & $44 \pm 16$ & $44 \pm 5$ \\
\hline 9. & $38 \pm 14$ & $43 \pm 8$ & $40 \pm 10$ & $28 \pm 18$ & $53 \pm 14$ \\
\hline
\end{tabular}

Values are means (d.p.m. per blastocyst) \pm SEM for 4 replicates of $21-25$ blastocysts per replicate (a total of $90-92$ blastocysts for each treatment). The identification of inositol phosphates is based on elution at the positions of the HPLC-pure $\left[{ }^{3} \mathrm{H}\right]$ linositol phosphate standards, $\operatorname{Ins}(4) \mathrm{P}, \operatorname{Ins}(1,4) \mathrm{P}^{2}, \operatorname{Ins}(1,4,5) \mathrm{P}_{3}$ and $\operatorname{Ins}(1,3,4,5) \mathrm{P}^{4}$, on a HPLC Mono $\mathrm{Q}$ column.

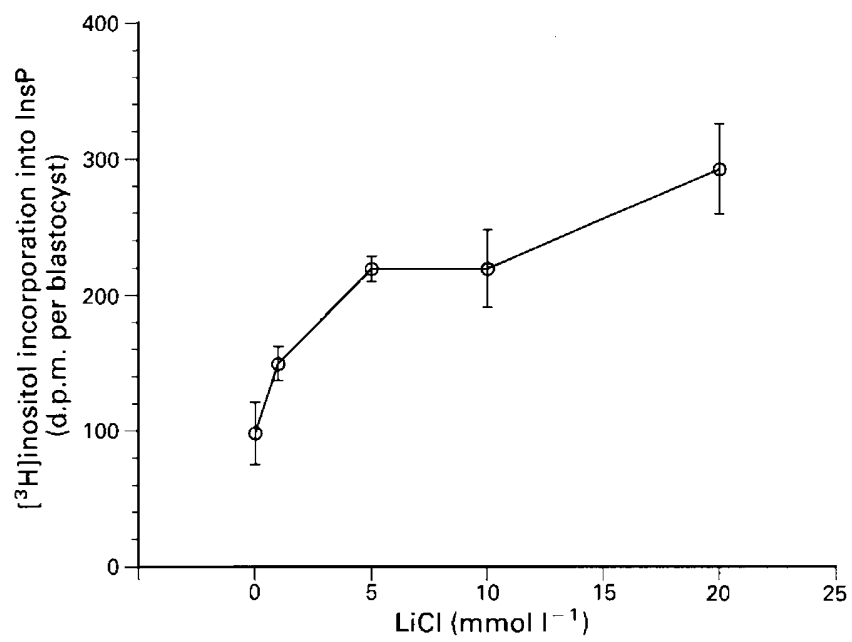

Fig. 2. Effects of incubation with different concentrations of lithium chloride for $1 \mathrm{~h}$ on accumulation of inositol monophosphates in rabbit blastocysts. Values are means (d.p.m. per blastocyst) \pm SEM for four replicates of 21-25 blastocysts per replicate (a total of 90-92 blastocysts for each treatment).

that blocking inositol monophosphatase caused significant accumulation of InsP indicates that the PtdIns cycle is turning over and active within rabbit blastocysts and thus may have a role in blastocyst development.

The increase in accumulation of InsP caused by lithium is in agreement with results in other tissues (reviewed by Sherman, 1989; Huckle and Conn, 1987). The magnitude of the increase in accumulation of InsP shown in our experiments varied from

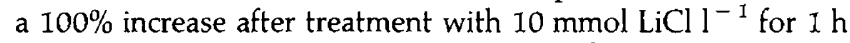
to a $200 \%$ increase with $20 \mathrm{mmol} \mathrm{LiCl} \mathrm{l}^{-1}$. Comparison with work in other laboratories with other tissues suggests that this increase is indicative of a significant but low level of relatively unstimulated cycle activity. Berridge et al. (1982) found that treatment with $10 \mathrm{mmol} \mathrm{LiCl} \mathrm{l^{-1 }}$ for $0.5 \mathrm{~h}$ in the absence of concomitant stimulation by phospholipase $\mathrm{C}$ agonists caused a $25 \%$ increase in accumulation of InsP by rat parotid tissue

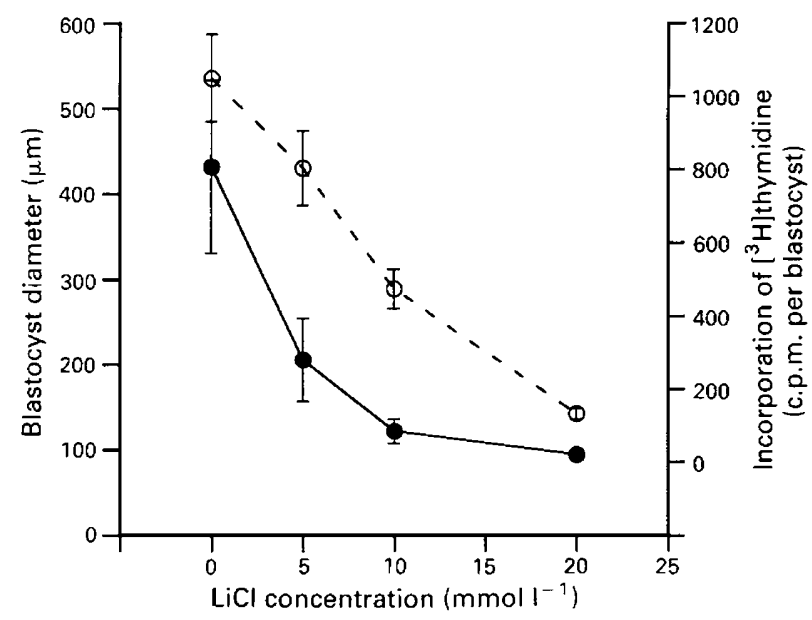

Fig. 3. Effects of culture with various concentrations of lithium chloride for 5 days on growth of rabbit blastocysts as measured by blastocyst diameter (- - ) and $\left[{ }^{3} \mathrm{H}\right]$ thymidine incorporation into acid-precipitable material $\left(--\mathrm{O}_{-}-\right)$. Values are means \pm SEM for six replicates of 4-14 blastocysts per replicate (a total of 35-41 blastocysts for each treatment).

slices, but in the presence of stimulation by agonist caused an increase of up to $600 \%$.

There are two explanations for the finding that PtdIns cycle activity in cultured rabbit blastocysts occurs at a relatively low (even if significant) rather than a high level. First, rabbit blastocyst growth in vitro is markedly less than growth in utero (reviewed by Kane, 1987) and this must be expected to result in a general depression of function. Second, the only potential source of exogenous peptide growth factors, which might be expected to stimulate Ptdlns cycle turnover, is from possible trace contamination of the $0.5 \% \mathrm{BSA}$ added to the medium.

Although the results reported here provide evidence for the presence of an active PtdIns cycle in rabbit blastocysts, they do not give any indication of the role that this cycle has in 

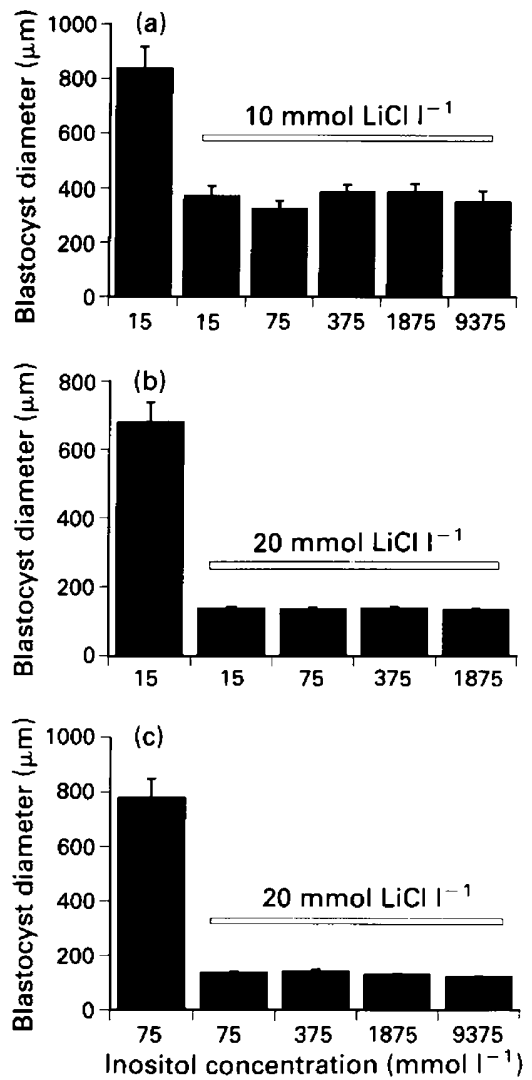

Fig. 4. Effects of cuiture with 10 and $20 \mathrm{mmol}$ lithium chloride $\mathrm{1}^{-1}$ and high concentrations of inositol for 3 days on rabbit blastocyst growth as measured by blastocyst diameter. Values are means \pm SEM(a) based on two replicates of seven to nine blastocysts per replicate (a total of 15-17 blastocysts per treatment); (b) based on three replicates of 9-11 blastocysts per replicate ( 30 blastocysts per treatment) and (c) based on two replicates of 10-13 blastocysts per replicate (21-24 blastocysts per treatment).

blastocysts. It is possible that the PtdIns cycle is active in utero and that it either responds to as yet unidentified uterine growth factors or functions as part of a paracrine intraembryonic system in which there is signalling between inner cell mass and trophoblast. What is needed to clarify this problem is the discovery of a growth factor that affects blastocyst development and at the same time causes increased or decreased activity of the Ptdins cycle.

The action of lithium in inhibiting inositol monophosphatase to cause an accumulation of InsP has been used as the basis of a method for amplifying phosphoinositide responses to stimulation of cells with phospholipase C-dependent growth factors and other agonists (Berridge et al., 1982; Huckle and Conn, 1987). Our results indicate that this method should also be useful for evaluating the effects of various peptide growth factors on PtdIns cycle turnover by preimplantation rabbit embryos and thus facilitate the search for such growth factors.

The effect of lithium in increasing accumulation of Ins $(1,4,5) \mathrm{P}_{3}$ (albeit to a more limited extent than InsP) in our experiments is surprising, as it is generally considered (Sherman, 1989) that lithium does not inhibit the $\operatorname{Ins}(1,4,5) \mathrm{P}_{3}$ phosphatase; Burgess et al. (1985) found no effect of $20 \mathrm{mmol}$
$\mathrm{LiCl} \mathrm{I}^{-1}$ on this enzyme in pancreatic acinar cells. In contrast, Ishima and Waku (1991) found that lithium treatment on rat brain increased Ins $(1,4,5) \mathrm{P}_{3}$ concentrations and suggested that it was due to the inhibition by lithium (Batty and Nahorski, 1987) of Ins $(1,4,5) \mathrm{P}_{3}$ kinase which converts $\operatorname{Ins}(1,4,5) \mathrm{P}_{3}$ to $\operatorname{Ins}(1,3,4,5) \mathrm{P}_{4}$.

Lithium treatment for $\mathrm{I} h$ in our experiments did not affect phosphoinositide concentrations. Downes and Stone (1986) reported that there is extremely close coupling of $\operatorname{PtdIns}(4,5) \mathrm{P}_{2}$ use and resynthesis from PtdIns $4 \mathrm{P}$ and PtdIns in parotid cells with the result that PtdIns $(4,5) \mathrm{P}_{2}$ is not readily depleted but PtdInsP and PtdIns4P are more readily decreased. The failure in our experiments to observe depletion of PtdInsP and PtdIns4P during lithium treatment may have been due to the fact that the $1 \mathrm{~h}$ treatment period was too short or that there was an insufficient PtdIns $(4,5) \mathrm{P}_{2}$ breakdown in relation to the size of the Ptdins pool.

Our results also show that long-term treatment with lithium markedly inhibited rabbit blastocyst growth. However, the lithium-induced inhibition of blastocyst growth and its associated accumulation of inositol phosphate could not be reversed by high concentrations of inositol in the culture medium. Thus the inhibitory effect of lithium on blastocyst growth was not specifically caused by inositol deprivation due to a lithiuminduced failure of inositol recycling and the PtdIns cycle activity is necessary for blastocyst growth.

It is possible that lithium may be inhibiting blastocyst growth by mechanisms other than its effects on the PtdIns cycle. Recently there have been reports indicating that lithium has a number of other sites of action within cells other than inhibition of inositol recycling. These include actions on protein kinase C (Casebolt and Jope, 1991; Divish et al., 1991), cyclic AMP (Divish et al., 1991; Risby et al., 1991), G protein receptors (Drummond, 1988; Newman et al., 1991) and gene expression (Dobner et al., 1988). One of these effects may be operating in rabbit blastocysis and may explain why the lithium-induced inhibition of blastocyst growth could not be reversed by high concentrations of inositol in the culture medium.

It is also possible that the failure to reverse the lithiuminduced inhibition of blastocyst growth with high extracellular concentrations of inositol may have been due to poor uptake of the excess inositol into blastocyst cells. Board

This work was supported by a grant from the Irish Health Research

\section{References}

Batty I and Nahorski SR (1987) Lithium inhibits muscarinic-receptor-stimulated inositol tetrakisphosphate accumulation in rat cerebral cortex Biochemical Journal 247 797-800

Batty IH, Letcher AJ and Nahorski SR (1989) Accumulation of inositol polyphosphate isomers in agonist-stimulated cerebral-cortex slices: comparison with metabolic profiles in cell-free preparations Biochemical Journal 258 23-32

Berridge MJ (1987) Inositol lipids and cell proliferation Biochimica et Biophysica Acta 907 33-45

Berridge MJ, Downes CP and Hanley MR (1982) Lithium amplifies agonistdependent phosphatidylinositol responses in brain and salivary glands Biochemical Journal 206 587-595 
Burgess GM, McKinney JS, Irvine RF and Putney JW, Jr (1985) Inositol 1,4,5trisphosphate and inositol 1,3,4-trisphosphate formation in Ca-mobilizinghormone-activated cells Biochemical Journal 232 237-243

Busa WB (1988) Roles for the phosphatidylinositol cycle in early development Philosophical Transactions of the Royal Society of London Series B 320 415-426

Casebolt TL and Jope RS (1991) Effects of chronic lithium treatment on protein kinase $C$ and cyclic AMP-dependent protein phosphorylation Biological Psychiatry 29 233-243

Divish MM, Sheftel G, Boyle A, Kalasapudi VD, Papolos DF and Lachman HM (1991) Differential effect of lithium on fos protooncogene expression mediated by receptor and postreceptor activators of protein kinase $\mathrm{C}$ and cyclic adenosine monophosphate: model for its antimanic action journal of Neuroscience Research 28 40-48

Dobner PR, Tischler AS, Lee YC, Bloom SR and Donahue SR (1988) Lithium dramatically potentiates neurotensin/neuromedin $\mathrm{N}$ gene expression Journal of Biological Chemistry 263 13983-13986

Downes CP and Stone MA (1986) Lithium-induced reduction in intracellular inositol supply in cholinergically stimulated parotid gland Biochemical journal 234 199-204

Drummond AH (1988) Lithium affects G-protein receptor coupling Nature 331 388

Fahy MM and Kane MT (1992) Inositol stimulates DNA and protein synthesis, and expansion by rabbit blastocysts in vitro Human Reproduction 7 550-552

Fahy MM and Kane MT (1993) Incorporation of $\left[{ }^{3} \mathrm{H}\right]$-inositol into phosphoinositides and inositol phosphates by rabbit blastocysts Molecular Reproduction and Development 34 391-395

Hallcher LM and Sherman WR (1980) The effects of lithium ion and other agents on the activity of myo-inositol-1-phosphatase from bovine brain journal of Biological Chemistry 255 10896-10901

Ham RG (1963) An improved nutrient solution for diploid Chinese hamster and human cell lines Experimental Cell Research 140 802-803

Harrison RAP, Roldan ERS, Lander DJ and Irvine RF (1990) Ram spermatozoa produce inositol 1,4,5-trisphosphate but not 1,3,4,5-tetrakisphosphate during the $\mathrm{Ca}^{2+}$ ionophore-induced acrosome reaction Cell Signalling 2 $277-284$

Huckle WR and Conn PM (1987) Use of lithium in measurement of stimulated pituitary inositol phospholipid turnover Methods in Enzymology 141 149-155

Ishima $Y$ and Waku K (1991) Accumulation of inositol 1,4,5-trisphosphate in the rat brain as a result of long-term administration of lithium Proceedings of the Japanese Academy B 67 121-124

Izquierdo L and Becker MI (1982) Effect of $\mathrm{Li}^{+}$on preimplantation mouse embryos Joumal of Embryology and Experimental Morphology 67 51-58
Kane MT (1987) In vitro growth of preimplantation rabbit embryos The Mammalian Preimplantation Embryo: Regulation of Growth and Differentiation in Vitro, pp 193-217 Ed. BD Bavister. Plenum Press, New York

Kane MT (1989) Effects of the putative phospholipid precursors, inositol, choline, serine and ethanolamine, on formation and expansion of rabbit blastocysts in vitro Joumal of Reproduction and Fertility $87275-279$

Kane MT and Bavister BD (1988) Vitamin requirements for development of eight-cell hamster embryos to hatching blastocysts in vitro Biology of Reproduction 39 1137-1143

Kane MT, Norris M and Harrison RAP (1992) Uptake and incorporation of inositol by preimplantation mouse embryos Journal of Reproduction and Fertility 96 617-625

Meek JL (1986) Inositol bis-, tris-, and tetrakisphosphate(s): analysis in tissues by HPLC Proceedings of the National Academy of Sciences USA 83 4162-4166

Meek JL and Nicoletti F (1986) Detection of inositol trisphosphate and other organic phosphates by high-performance liquid chromatography using an enzyme-loaded post-column reactor Journal of Chromatography 351 303-311

Newman ME, Shapira B and Lerer B (1991) Effects of lithium and desimipramine on 2nd messenger responses in rat hippocampus: relation to $G$ protein effects Neuropharmacology 30 1297-1301

Risby ED, Hsiao JK, Manji HK, Bitran J, Moses F, Zhou DF and Potter WZ (1991) The mechanisms of action of lithium II. Effects on adenylate cyclase activity and $\beta$-adrenergic receptor binding in normal subjects Archives of General Psychiatry 48 513-524

Roldan ERS and Harrison RAP (1989) Polyphosphoinositide breakdown and subsequent exocytosis in the $\mathrm{Ca}^{2}+$ /ionophore-induced acrosome reaction of mammalian spermatozoa Biochemical Journal 259 397-406

Sherman WR (1989) Inositol homeostasis, lithium and diabetes Inositol Lipids in Cell Signalling, pp 39-79 Eds RH Michell, AH Drummond and CP Downes. Academic Press, London

Simonnet G (1990) The scintillation counter Radioisotopes in Biology: A Practical Approach, pp 31-85 Ed. RJ Slater. Oxford University Press, Oxford

Steel RGD and Torrie JH (1960) Principles and Procedures of Statistics. McGrawHill Book Company, Inc., New York

Tilly BC and Moolenaar WH (1989) Inositol lipids in growth factor action Inositol Lipids in Cell Signalling, pp 39-79 Eds RH Michell, AH Drummond and CP Downes. Academic Press, London

Whitaker M (1989) Phosphoinositide second messengers in eggs and oocytes Inositol Lipids in Cell Signalling. pp 39-79 Eds RH Michell, AH Drummond and CP Downes. Academic Press, London 